\title{
Employment protection, international specialization, and innovation ${ }^{1}$
}

\author{
Gilles Saint-Paul \\ CERAS, DELTA, and CEPR
}

This version: May 1997 (First version: January 1996)

\footnotetext{
${ }^{1}$ This paper was written while the author was visiting the I.M.F Research Department. I am grateful to David Coe, Daniel Cohen, and participants at the conference on unemployment, Florence, May 1996, the European Economic Association conference, Istanbul, August 1996, and the European Summer Symposium on Macroeconomics, Athens, May 1997 for hepful comments and suggestions. Financial support from a MIRAGE grant is also gratefully acknowledged.
} 


\section{Introduction}

European labor market institutions have long been blamed for this region's unemployment problem. But the theoretical and empirical research has not been too conclusive about the employment effects of these institutions. From a theoretical viewpoint, there may exist beneficial offsetting effects on employment of firing costs, minimum wages or unemployment benefits (See Alogoskoufis et al. (1995)); from an empirical viewpoint, the evidence is fragmentary and contradictory.(See Layard et. al. (1991)).

However, labour market rigidities may have other, far more damaging, yet less studied, effects on long-term productivity growth by affecting the pattern on international specialization and innovation. ${ }^{1}$ This is far from a theoretical possibility, since there has been growing concern that Europe might be losing ground in the "technology race" which increasingly takes place between the United States and Japan.

As a matter of fact, Research and Development expenditures, as a percent of GDP, are about $20 \%$ higher in the United States and Japan than in Europe. ${ }^{2}$ There is also clear evidence that the U.S. and Japan are substantially better than Europe at producing and exporting high-tech goods. Thus, Butler (1992) shows that high-tech manufactures represent 30 percent of U.S. manufacturing output in 1990, and 35 percent of Japanese manufacturing output, while the corresponding figure for Germany (the most technologically advanced Western European country) is just 20 percent. Note that

\footnotetext{
${ }^{1}$ The effects of job protection on economic growth have been studied by Hopenhayn and Rogerson (1993), in the context of a model where job protection slow labor reallocation from old to new sectors. The argument is distinct from the one developed here.

${ }^{2}$ This figure is based on OECD Main Science and technology Indicators, 1995/1, table 24 (Belgium: 1991). $20 \%$ is a rough figure; while the gap between the U.S. and Germany is les than $10 \%$, the gap between the U.S. and France or the U.K. is more than $15 \%$, while Belgium, the Netherlands, Spain and Italy have an R \& D intensity which is less than half that of the U.S.

A comparison between the U.S and Europe as a whole therefore gives a clear picture of a technological advantage in favor of the U.S. By contrast, the picture is less clear if we compare the U.S with Germany. Unfortunately, the relevant basis of comparison is unclear. On the one hand, one may argue that living standards are more similar to U.S. ones in Germany than in Europe as a whole. On the other hand, Germany's strong technological position may reflect the fact that it is the region in Europe that has a locational competitive advantage in high technology, as do California, Texas or Massachusetts in the U.S. Under that interpretation, the relevant comparison is either between Germany and American high-tech regions, or between the U.S. as a whole and Europe as a whole.
} 
in all three countries, these figures show an upward trend, but in Germany it has stagnated between 1985 and 1990, whereas in the U.S. it has risen from 25 percent to 30 percent, and in Japan from 24 percent to 35 percent. Similarly, Kravis and Lipsey (1989), have computed indices of comparative advantage in high tech, medium tech and low tech goods defined as the ratio of the export share in the corresponding technology group over total export shares. They report that in 1986, Germany's comparative advantage in high tech goods had dropped to 0.86 from 1.08 on 1966. A the same time, the U.S. had enhanced its comparative advantage from 1.4 to 1.6, and Japan had slightly deteriorated from 1.7 to 1.6. Similarly, De Woot (1988) reports that the European industry has kept losing market shares in high-tech industries such as electronics.

A paradigmatic illustration of a mature, "medium tech", stable good in which Europe as a comparative advantage is the automobile tire industry, where Michelin of France is a world leader. Interestingly, Michelin is also a dynamic innovator. ${ }^{3}$ But its innovations are always improvements on an existing, well-defined good whose demand is clearly established and fairly stable. This is to be compared with the proliferation of new goods and risky undertakings that come out of the Silicon Valley.

In this paper we want to suggest that there may be a connection between these developments and labor market institutions. We develop a model to analyze the implications of labor market rigidities - more specifically, here, firing costs - on incentives for R \& D and international specialization. The key idea is that, to avoid paying the firing cost, the country with a rigid labor market will tend to produce goods with a relatively stable demand, at a late stage of their product life cycle, such as refrigerators or automobile tires. Under international trade, an international product cycle emerges where, roughly, new goods are first produced in the low firing cost country and then, after having reached a more mature, more stable, stage, move to the high firing cost country. This international allocation of production in turn has implication for the allocation of innovative activity across countries. More specifically, we show that, to the extent that countries have an incentive to innovate in goods where they have a comparative advantage, "flexible" economies will tend to engage in "primary" innovation, that is, the introduction of new goods, while "rigid economies" will rather engage in "secondary" innovation, that is reduction in the cost of producing existing,

\footnotetext{
${ }^{3}$ See Scherer (1991).
} 
mature goods. The model therefore shed lights on why Europe appear as less "high tech" than the United States. ${ }^{45}$

The paper is organized as follows. Section 2 sets up the basic closed economy model of differentiated products, and shows that if a firm's death rate is falling with the maturity of its product, firing costs introduce a negative dependence of the marginal cost of producing a good on its maturity. This implies that production will be distorted in favor of mature goods and against young goods. Section 3 extends this analysis to an open economy, and shows that if countries differ across their labor market institutions, there will be a product life cycle. New goods will be produced in the "flexible country", and move to the rigid one after a while. Section 4, which is the main one, modifies the model to allow both for endogenous invention of new goods (primary innovation) and cost-reducing innovation (secondary innovation). We show that, to the extent that the scope for cost-reductions is bounded, the high firing cost country will typically specialize in secondary innovation, thus securing monopoly power on relatively stable products, while the low firing cost one will specialize in primary innovation.

\section{The model}

The model is based on a standard structure, popularized by Dixit and Stiglitz (1977), and introduced into the context of innovation and growth by Romer (1990), and Grossman and Helpman (1991). At each instant of time there

\footnotetext{
${ }^{4} \mathrm{It}$ is often argued that Japan is a rigid country, most notably because of its tradition of life-time employment, and that despite that it is good at inventing and producing high tech goods. However, such tradition of life-time employment is not the outcome of labour regulation, which is typically ranked as less restrictive than Europe (See OECD, 1994). Furthermore, life-time employment only prevails in large groups that can use subcontractors and internal mobility to adjust to demand fluctuations. Such internal mobility is far more restricted in European countries such as France, where large firms must have the consent of unions and/or the administration for many internal restructuring activities, that are typically assimilated to collective dismissals (See e.g. Abowd and Kramarz, 1995).

${ }^{5}$ It may be argued that most of R\&D firms are small, so that if they were located in Europe they would probably fall below the employment threshold beyond which employment protection binds. However, most of the rewards from setting up such firms comes from being eventually bought by a larger firm, and because of labor regulation large firms in Europe will be more reluctant to engage into such a venture, which ex-ante discourages entry of small R\&D firms.
} 
are $N_{t}$ goods available. All consumers have the same utility function in those goods,

$$
V=\int_{0}^{+\infty} u\left(C_{t}\right) e^{-\rho t} d t
$$

where $C_{t}$ is the aggregate consumption index given by

$$
C_{t}=\left(\int_{1}^{N_{t}} c_{j t}^{\alpha} d j\right)^{1 / \alpha} .
$$

Maximization of utility yields the traditional isoelastic demand:

$$
c_{j t}=\left(\frac{X_{t}}{p_{t}}\right)\left(\frac{p_{j t}}{p_{t}}\right)^{-\sigma},
$$

where $\sigma=1 /(1-\alpha)$ is the elasticity of substitution, and $X_{t}$ is nominal income. The corresponding aggregate price index is

$$
p_{t}=\left(\int_{1}^{N_{t}} p_{j t}^{1-\sigma}\right)^{1 /(1-\sigma)}=1
$$

We have normalized this price to one, so that wages are expressed in terms of true living standards. We assume $\sigma>1$, which ensures that the introduction of new goods is valued by consumers, and that monopolies will produce in strictly positive quantities.

Goods are not always demanded. After a while, they disappear from the utility function. We assume that this occurs according to a hazard function $h(s)$, where $s$ is the age of the good. We assume $h^{\prime}<0$, that is, hazard rates are declining with age. Thus, new goods have a higher probability of becoming obsolete than old goods. The idea is that it takes time for standards to be established and for consumers to learn whether a good is really useful or not. Old goods are those who have survived this selection process. So, washing machines are less likely to disappear than large size laser discs.

Thus production of an existing good is a risky activity, more so when the good is young and not well established.

The declining profile of decay rates is consistent with the empirical analysis of plant death rate in Dunne et al. (1989), and in line with the evidence in Davis and Haltiwanger (1992) that job destruction rates declines with age. While in this section we assume for simplicity that the good disappears with 
a hazard rate which decreases with age, what really matters is that any producer will disappear with a probability which decreases with the maturity of the good (which is what the evidence in Dunne et al. is really about). Such an event may be due to the fact that the good itself disappears, as we assume here, or to the fact that the producer is driven out of business by more efficient producers, as is assumed in section $4 .^{6}$

We assume a "rigid" labor market, in the sense that there are firing costs. These are modelled as a tax on job destruction which is paid to the government and rebated to local consumers in a lump-sum way. ${ }^{7}$ There are no other rigidities, however, so that wages adjust downward to restore full employment.

Firing costs matter, however, because they affect the terms of trade between producing new goods and old goods. In steady state, when the demand curve for a given good is stable, there is no reason for producers to reduce their labor force as long as the good is demanded. ${ }^{8}$ This is because as time passes the hazard rate falls so that the goods become ever less risky to produce. Now, with probability $h(s)$ per unit of time, the good disappears and employers have to fire their workers. We assume a firing cost indexed on the wage and equal to $F w$, where $w$ is the prevailing wage. Then, clearly, the shadow cost of employing a worker to produce a good aged $s$ is $w(1+h(s) F)$. One way to see this is as follows. Let $C(s)$ be the present discounted value of the costs incurred by employing a worker in the production of a good of maturity $s$ until the firm disappears. Then $C(s)$ satisfies the following Bellman equation:

$$
0=w-(r+h(s)) C(s)+C^{\prime}(s)+h(s) F w
$$

\footnotetext{
${ }^{6} \mathrm{~A}$ downward profile of death rates may thus be due to the convergence of both the selection process for goods and the selection process for producers.

${ }^{7}$ What is really needed for our results is that demand is more volatile for young goods than for established goods. Here it takes the simplified form of a good disappearing with a probability which declines with age.

This brings up the question of whether one is dealing with bankruptcy costs rather than firing costs. While it is true that bankruptcy costs are lower in the U.S. too, the distinction between the two is clearer in models than in reality, where firms gradually learn about their viability, and expect that if they disappear it will occur after some attempts to restructure by shedding labor. Ex-ante, firing costs therefore increase the perceived costs of bankruptcy.

${ }^{8}$ In fact, they will increase their labor force, as their shadow marginal cost of labor is reduced.
} 
This has the standard asset value interpretation. The rate of return on $C, r C$, is equal to the dividend $w$ plus the expected capital gains $C^{\prime}(s)+$ $h(s)(F w-C)$. Hence $C(s)$ would be the same if instead the firm could freely fire the worker when running out of business and had to pay him a rental rate of $w(1+h(s) F)$. Thus this is the adequate shadow marginal cost of labor.

Thus, the shadow marginal cost of producing a good is decreasing with the maturity of that good.

Let us first characterize the steady state equilibrium in a closed economy. We can assume that goods are produced by perfect competitors. ${ }^{9}$ The production function for any good $i$ has constant returns with labor as the sole input and unit productivity: $y_{i}=l_{i}$.

It follows that the price of any good of maturity $s$ is equal to the marginal cost, given by:

$$
p(s)=w(1+h(s) F),
$$

Output of a good of vintage $s$ is therefore given by

$$
x(s)=X w^{-\sigma}(1+h(s) F)^{-\sigma},
$$

where $X$ is aggregate income in steady state. Therefore, older goods are produced in larger quantities because their shadow marginal cost is lower. This is a distortion induced by the employment protection legislation: the larger the firing costs, the more the economy will produce mature goods rather than young goods.

Before we extend the model to a closed economy, let us briefly indicate how it can be closed. To compensate for the disappearance of some goods, we assume that a constant, exogenous, inflow $n_{0}$ of new blueprints is introduced per unit of time, so that the number of goods of vintage $s$ is given by:

$$
n(s)=n_{0} e^{-\int_{0}^{s} h(u) d u} .
$$

The model is then simply closed by writing down equilibrium in the goods market, and the price normalization equation. This allows to compute the equilibrium wage and GDP levels $w$ and $X$. If total employment is normalized to one, the full employment condition can be written as:

$$
1=\int_{0}^{+\infty} n(s) x(s) d s=n_{0} X w^{-\sigma} \int_{0}^{+\infty} e^{-\int_{0}^{s} h(u) d u}(1+h(s) F)^{-\sigma} d s .
$$

\footnotetext{
${ }^{9}$ This is no longer the case in section 4 where monopoly power is needed to create incentive for innovation.
} 
And the price normalization equation is

$$
1=n_{0} w^{1-\sigma} \int_{0}^{+\infty} e^{-\int_{0}^{s} h(u) d u}(1+h(s) F)^{1-\sigma} d s
$$

Finally, in steady state the rate of time preference must equal the real interest rate, which plays no role here, but will come into the analysis later: ${ }^{10}$

$$
r=\rho
$$

Note that firing costs would be neutral if $h$ were constant across goods. In that case downward wage adjustment maintains full employment, and firing costs do not distort relative prices. Firing costs matter, here, only because sectors differ in the volatility of their demand.

\section{Introducing international trade}

The main insight gathered from the previous section is that employment protection will bias the allocation of resources in favor of mature goods. How does international trade affect this conclusion.

We consider two economies, one, (designated by an index $i=1$ ), without firing costs, the other with a firing cost equal to $F$. Except for firing costs, the two economies are identical. In particular, all consumers have the same utility function given by (1) and (2). All goods are tradeable.

Because of firing costs, country 2 will have a comparative advantage in mature goods and country 1 in young goods. This is because the shadow marginal cost in country 2 for a good of vintage $s$ is $c_{2}=w_{2}(1+h(s) F)$, while it is equal to $c_{1}=w_{1}$ in country 1 . Therefore, country 2 will specialize in goods of a maturity greater than $\tilde{s}$, and country 1 in goods younger than $\tilde{s}$, where $\tilde{s}$ is such that

$$
w_{2}(1+h(\tilde{s}) F)=w_{1} .
$$

This specialization pattern is illustrated in figure $1 .{ }^{11}$ The discrepancy between labor market institutions across the two countries introduces an international product cycle, such that goods are first produced in the low firing

\footnotetext{
${ }^{10}$ Contrary to Grossman-Helpman, there is no dynamic externality governing the cost of R \& D. Sustained growth is thus impossible and the economy converges to a stationary equilibrium. A constant consumption then requires equality between the rate of time preference and the interest rate.

${ }^{11}$ This structure is similar to Dornbusch, Fischer, and Samuelson (1977), where here all the comparative advantage pattern comes from labor market regulation.
} 
cost country and then, when they reach maturity $\tilde{s}$, their production is transferred to the high firing cost one.

The model is simply closed by writing the full employment equations in each country, and the price normalization equation. We get:

$$
\begin{gathered}
1=n_{0} X w_{1}^{-\sigma} \int_{0}^{\tilde{s}} e^{-\int_{0}^{s} h(u) d u} d s . \\
1=n_{0} X w_{2}^{-\sigma} \int_{\tilde{s}}^{+\infty} e^{-\int_{0}^{s} h(u) d u}(1+h(s) F)^{-\sigma} d s .
\end{gathered}
$$

These are the two full employment equations for countries 1 and 2, respectively, where $X$ is now world income, while the price normalization equation is:

$$
1=n_{0} w_{1}^{1-\sigma} \int_{0}^{\tilde{s}} e^{-\int_{0}^{s} h(u) d u} d s+n_{0} w_{2}^{1-\sigma} \int_{\tilde{s}}^{+\infty} e^{-\int_{0}^{s} h(u) d u}(1+h(s) F)^{1-\sigma} d s
$$

\section{Implications for the pattern of innovation}

In this section, we want to draw the implications of the pattern of specialization derived in the previous section for the allocation of innovative activity across the two countries.

For this purpose, we extend the model in the following way. Each country is now endowed with a fixed number of researchers, who can engage in either 'primary' or 'secondary' innovation. Primary innovation consists in introducing new goods, while secondary innovation consists in producing existing goods more efficiently, i.e. at a lower cost. ${ }^{12}$ Primary innovators get a patent granting them monopoly over the production of the good. We assume that a secondary innovator obtains a patent which allows him to produce the existing good despite the original inventor's (and previous secondary innovator's) patent: that is, the new process is treated as a new good by patent authorities. The original inventor's monopoly is therefore de facto eliminated by the first secondary innovation, while the latest secondary innovator retains monopoly over the most efficient production technique for a given good.

\footnotetext{
${ }^{12}$ This distinction is different from the one analyzed by Aghion and Howitt (1994), between Research and Development.
} 
We assume that technology is not transferable abroad, so that to reap monopoly profits from a patent an innovator can neither sell the patent to a foreign buyer nor produce the good abroad by himself. ${ }^{13}$

We will also assume, for simplicity, that secondary innovations are drastic, that is the implied cost reduction is large enough to drive former producers of the good out of business. Part of the death rate $s$ analyzed above is now the outcome of obsolescence driven by secondary innovation (this theme of obsolescence has been emphasized by Aghion and Howitt (1992)). We also assume that goods disappears with constant probability $h$ per unit of time, which is another contribution to a producer's death rate.

A key assumption is that secondary innovation has strong decreasing returns, so the arrival rate of further secondary innovations is reduced each time a good is subject to a secondary innovation. This decreasing returns assumption generates the downward profile of exit rate upon which our analysis has been based so far. Indeed, to keep the model tractable, we will only allow for one secondary innovation to take place once a good has been invented.

The key result we obtain is that the low firing cost country will be specialized in primary innovation, while the high firing cost one will engage in secondary innovation. This is because the threat of secondary innovations makes new goods more vulnerable to obsolescence than those who have already been subject to secondary innovations, and because firing costs make country 2 more averse to obsolescence.

We now turn to how the model can be extended to encompass these effects. We only discuss how firing costs affects the world allocation of R \& D. The complete solution of the model is described in the appendix.

Each country has a constant number of researchers $z_{i}$. The remaining labor force $1-z_{i}$ is engaged in direct production activity. Researchers can be allocated to either primary innovation, referred to as "invention", or secondary innovation (referred to as "imitation"). Primary innovation consists of a new blueprint (as in Romer (1990), and Grossman and Helpman (1991)). One unit of labor allocated to primary innovation during a small time interval $d t$ yields on average $\gamma d t$ new goods. $\gamma$ is exogenous and represents productivity in the R \& D sector. Newly invented goods can be produced with a unit

\footnotetext{
${ }^{13}$ More generally, we could assume that producing abroad is more costly than producing at home. An alternative assumption which would be equivalent is that technology is more likely to be "stolen" if transferred abroad.
} 
labor requirement, until the time a secondary innovation occurs. At that time an imitator finds a way to produce it with a unit labor requirement equal to $\lambda<1$ (This is what drives growth in Aghion and Howitt (1992)). The imitator retains monopoly over this production process. Furthermore, we assume that $\lambda$ is small enough to drive the original inventor out of business. That is, the monopoly price of the imitator with labor cost $\lambda$ is lower than the cost of the original inventor. Only one secondary innovation can happen to each good, and it may take place in any of the two countries regardless of where the good is originally produced. Goods that have not being hit by imitation will henceforth be called "high-tech" (H), or "young", while goods that have been hit by imitation will be called "low-tech" (L) or "mature". Like invention, imitation is costly. One unit of labor devoted to imitation during a small time interval $d t$ allows to imitate on average $\rho d t$ high-tech goods. Unlike $\gamma, \rho$ is endogenous. It will be lower, the lower the number of high-tech goods available and the higher the number of researchers competing to imitate existing goods. Similarly, any high-tech good has an endogenous probability $\nu$ per unit of time of being imitated. $\nu$ varies inversely with $\rho$ : it is larger, the larger the number of researchers engaged in imitation, and the smaller the number of high-tech goods available.

The efficiency of the imitation process is summarized by the use of a "matching function", borrowed from the theory of job search ${ }^{14}$, which relates the flow of imitation to the number of researchers allocated to imitation and the number of high-tech goods available for imitation. ${ }^{15}$ Let $z_{i}^{H}$ the number of researchers involved in invention in country $i$, and $z_{i}^{L}$ the number of researchers involved in imitation, with $z_{i}=z_{i}^{H}+z_{i}^{L}$. Let $n_{i}^{H}$ the number of high-tech goods produced in country $i$, and $n_{i}^{L}$ the corresponding number of low-tech goods. Then the number of goods imitated per unit of time is given by $m\left(n^{H}, z^{L}\right)$, where $n^{H}=n_{1}^{H}+n_{2}^{H}$ is the total number of hightech goods produced worldwide, and $z^{L}=z_{1}^{L}+z_{2}^{L}$ is the total number of researchers engaged in imitation. ${ }^{16} m$ is the matching, or imitation function,

\footnotetext{
${ }^{14}$ Pissarides (1990).

${ }^{15}$ While this specification is natural, to my knowledge it has not been used before in the literature. For example, Grossman and Helpman (1991) assume an imitation technology similar to the invention technology, with no effect on the probability of successfully imitating of either the number of products available for imitation or the number of imitators competing to imitate.

${ }^{16}$ Thus, a good produced abroad can be as easily imitated as a good produced at home. More generally, this assumption could be relaxed by using several matching functions of
} 
which is increasing in its two arguments and has constant returns to scale. More specifically we shall use a Cobb-Douglas specification $m\left(n^{H}, z^{L}\right)=$ $m .\left(n^{H}\right)^{\alpha}\left(z^{L}\right)^{1-\alpha}$. The matching function captures the fact that high-tech goods are the prey of imitators, and that congestion arises when the prey becomes scarcer relative to the predator. The flow probability of imitating is thus given by:

$$
\rho=\frac{m\left(n^{H}, z^{L}\right)}{z^{L}}=m\left(\frac{n_{H}}{z_{L}}\right)^{\alpha},
$$

while the flow probability of being imitated is:

$$
\nu=\frac{m\left(n^{H}, z^{L}\right)}{n^{H}}=m\left(\frac{n_{H}}{z_{L}}\right)^{\alpha-1}
$$

An inverse relationship between $\rho$ and $\nu$ (formally similar to the factorprice frontier) can then be obtained, which we shall call the hazard frontier:

$$
\left(\frac{\rho}{m}\right)^{1 / \alpha}=\left(\frac{\nu}{m}\right)^{1 /(\alpha-1)}
$$

We now study the allocation of research activity across invention and imitation in each country. We assume perfect competition in the labor market and free entry of firms into the research sector. Therefore, the wage of a researcher must be equal to the expected present discounted value of the monopoly profits generated by his future primary or secondary innovations.

While the death rate of a good does not fall with the maturity of the good, the death rate of its producer does. A primary innovation is riskier than a secondary one because it is more exposed to obsolescence. Thus, secondary innovation gives monopoly power over more secure goods than primary ones, because subsequent imitation cannot occur. ${ }^{17}$ Thus, the death rate of a monopoly which produces a high-tech good is $h+\nu$, while the death rate of a monopoly which produces a low-tech good is just $h$.

We now compute the expected present discounted value of the profits generated by an invention and an imitation, depending on the country where it takes place. The world aggregate price index is still normalized to one, so

the type $m_{i j}\left(n_{i}^{H}, z_{j}^{L}\right)$ to describe the flow of goods produced in country $i$ and imitated in country $j$.

${ }^{17}$ More generally, with secondary imitation alowed to take place several times but with decreasing returns, the death rate of monopoly profits will be a decreasing functions of the number of secondary imitations that have occured. 
that the demand for any good of price $p$ is $X p^{-\sigma}$, where $X$ is world income. Consequently the monopoly price of any good of unit cost $\omega$ is $\mu \omega$, with $\mu=\sigma /(\sigma-1)$. Let $w_{i}$ the equilibrium wage rate for production workers in country $i$. The relevant unit costs are given by:

1. $w_{1}$ for a high-tech good produced in country 1 .

2. $\lambda w_{1}$ for a low-tech good produced in country 1 .

3. $w_{2}(1+(h+\nu) F)$ for a high-tech good produced in country 2 .

4. $\lambda w_{2}(1+h F)$ for a low-tech good produced in country 2 .

We can already see that country 2 has a comparative advantage in lowtech goods, as was argued in the previous section. We now show that it implies that its researchers will specialize in imitation rather than invention.

For this, let us compute the profits generated by invention and imitation, in steady state, in each country. In country 1 , these are equal to:

$$
\Pi_{H 1}=\frac{(\mu-1) X w_{1}^{1-\sigma} \mu^{-\sigma}}{r+\nu+h}
$$

for an invention, and:

$$
\Pi_{L 1}=\frac{(\mu-1)\left(\lambda w_{1}\right)^{1-\sigma} X \mu^{-\sigma}}{r+h}
$$

The numerator is equal to the steady state profit per unit of time, while the denominator is the appropriate discount rate, i.e. the sum of the real interest rate and the firm's death rate, which comes from either the good's disappearance or a secondary innovation for high-tech goods, or just from the first source for low-tech goods.

Similarly, for the high firing cost country we get:

$$
\begin{gathered}
\Pi_{H 2}=\frac{(\mu-1) X\left(w_{2}(1+(h+\nu) F)\right)^{1-\sigma} \mu^{-\sigma}}{r+\nu+h}, \\
\Pi_{L 2}=\frac{(\mu-1)\left(\lambda w_{2}(1+h F)\right)^{1-\sigma} X \mu^{-\sigma}}{r+h},
\end{gathered}
$$

Concerning the cost of $\mathrm{R} \& \mathrm{D}$, if we denote by $\phi_{i}$ the wage of researchers in country $i$, then the cost of creating one blueprint is $C_{H 1}=\phi_{1} / \gamma$ in country 1 , while the cost of imitating one good is $C_{L 1}=\phi_{1} / \rho$. As for country 2 , we allow for a flow probability $h_{R}$ that a research job is destroyed (for 
whatever reason), in which case the firing cost has to be paid. We thus get $C_{H 2}=\phi_{2}\left(1+h_{R} F\right) / \gamma$ and $C_{L 2}=\phi_{2}\left(1+h_{R} F\right) / \rho$. We assume free entry of firms into the $\mathrm{R} \& \mathrm{D}$ sector. This implies that in equilibrium one must have $\operatorname{Max}\left(\Pi_{H i}-C_{H i}, \Pi_{L i}-C_{L i}\right)=0$. There are three possible regimes: full specialization of country $i$ in invention if $\Pi_{L i}-C_{L i}<0$, full specialization in imitation if $\Pi_{H i}-C_{H i}<0$, and production of both invention and imitation if $\Pi_{L i}-C_{L i}=\Pi_{H i}-C_{H i}=0$. One convenient way to analyze these possibilities is to define the return to invention relative to imitation in country $i$ as:

$$
R_{i}=\frac{\Pi_{H i} / C_{H i}}{\Pi_{L i} / C_{L i}}
$$

Clearly, country $i$ will only innovate if $R_{i}>1$, only imitate if $R_{i}<1$, and may do both if $R_{i}=1$. Using the above formulae we can compute $R_{1}$ :

$$
R_{1}=\frac{\lambda^{\sigma-1}(r+h) \gamma}{\rho(r+\nu+h)}
$$

and

$$
R_{2}=\frac{\lambda^{\sigma-1}(r+h) \gamma}{\rho(r+\nu+h)}\left(\frac{1+(h+\nu) F}{1+h F}\right)^{1-\sigma}
$$

The relative return to invention in any country falls both with the success rate of an imitation $\rho$ and the probability of being imitated $\nu$. Consequently, the locus delimitating the three regimes for country $i$ will be a downward sloping curve $H_{i}$ in the $(\nu, \rho)$ plane, given by $R_{i}=1$, and the (pure) invention regime prevails in country $i$ when the world economy is (strictly) below $H_{i}$.

It can already be seen that $R_{2}<R_{1}$. The return to invention, relative to imitation is always smaller in country 2 because invention yields high-tech goods that are more vulnerable to obsolescence than mature ones, and firing costs bias the cost structure in favor of the latter. Therefore, country 2 will always imitate "more" than country 1 . If for example country 1 does both imitation and invention, implying $R_{1}=1$, then country 2 will only imitate.

The closing of the model in terms of $\rho$ and $\nu$ is illustrated on figure 2. To close the model we first need to write a steady state relationship:

$$
\gamma z_{H}=(h+\nu) n_{H},
$$

which says that the outflow of high-tech goods must be equal, in steady state, to the inflow of new blueprints. Together with (11) and (12) this implies:

$$
\rho=\frac{\nu \gamma}{h+\nu} \frac{z_{H}}{z_{L}}
$$


This relationship simply tells us that given the number of researchers devoted to invention and imitation, an increase in the probability of imitation (say due to a shift in $m$ ) must be matched by a rise in the probability of being imitated.

Equilibrium is then determined by the intersection of the hazard frontier with a locus $A B C D$ representing the equilibrium allocation of researchers across the two activities in steady state. This locus is derived as follows. First, note that as long as $\rho$ and $\nu$ are strictly positive (which must hold because of the hazard frontier), both imitation and invention must co-exist. Without invention no goods would be available, and because the matching function satisfies the Inada conditions the first inframarginal unit of research devoted to imitation succeeds at an infinite pace and is thus costless. Therefore, the world economy cannot be located above $H_{1}$ or below $H_{2}$. Second, $z_{H}>z_{1}$ if country 2 innovates (implying $z_{L}<z_{2}$ ), $z_{H}=z_{1}$ if country 2 does not innovate and country 1 does not imitate, and $z_{H}<z_{1}$ if country 1 imitates. This, together with (14), implies that the economy must respectively lie above, on, or below the $R R$ locus defined by $\rho=\frac{\nu \gamma}{h+\nu} \frac{z_{1}}{z_{2}}$, if it is on $H_{2}$, between $H_{1}$ and $H_{2}$, or on $H_{1}$. Putting the relevant portions of $H_{1}, H_{2}$, and $R R$ together we get the ABCD locus. While multiplicity of equilibria may in principle arise, we rule it out in figure 2 by assuming that the hazard frontier is steeper than $H_{1}$ and $H_{2}{ }^{18}$

An increase in the firing cost $F$ is illustrated on figure 3, for the case where country 2 innovates. ${ }^{19} H_{2}$ shifts downwards, implying a rise in $\nu$ and a fall in $\rho$. More researchers in country 2 imitate, fewer innovate. Consequently the probability of imitating falls, that of being imitated rises. The increase in $F$ may potentially move the economy to the zone where country 2 does not innovate at all.

How does openness affect the equilibrium allocation of invention and imitation? In the closed economy case, since both invention and imitation must

\footnotetext{
${ }^{18}$ Multiplicity may arise because of the following mechanism. An increase in resources devoted to imitation lowers the returns to imitation, since there are fewer high-tech goods to be imitated, but also the returns to innovation, since there is a greater chance to be imitated. If the latter effect dominates, the return to imitation relative to innovation actually rises, which validates the incipient increase in the resources devoted to imitation. Consequently, there is local complementarity between imitation and its relative return, which may lead to multiple equilibria.

${ }^{19}$ If country 2 only imitates, the increase in the firing cost has no impact on the allocation of R \& D, since its incentives to innovate are further reduced.
} 
co-exist, equilibrium is simply determined by the intersection of the hazard frontier with the relevant $H_{i}$ locus. An increase in $F$ would still shift it downwards, and consequently research would be reallocated away from invention into imitation, as in the open economy. Country 1 thus has a higher fraction of research devoted to invention than country 2 (Figure 4): $\rho$ is higher, and $\nu$ lower, in country 1 . When frontiers are opened, the high firing cost economy may fully specialize in imitation if world equilibrium is off its $H_{2}$ locus, as in figure 4. Even if this is not the case (that is, if the world equilibrium for $(\nu, \rho)$ lies on the portion of ABCD which coincides with $\left.H_{2}\right)$, country 2 's researchers will be moved from invention to imitation despite the fact that the world values of $\rho$ and $\nu$ (and therefore the world ratio of invention over imitation activity $z_{H} / z_{L}$ ) remain equal to their initial values in country 2. This is because of a Rybscynski effect: given that all the $z_{1}$ researchers in country 1 now fully specialize in invention, $z_{2 H} / z_{2 L}$ must fall in order to maintain the world value of $z_{H} / z_{L}$, which is now $\left(z_{1}+z_{2 H}\right) / z_{2 L}$, equal to the initial value of $z_{2 H} / z_{2 L}$ in country 2 . We are also able to show that openness makes country 2 's share of researchers engaged in invention more vulnerable to the firing cost $F$ (see appendix).

\section{Conclusion}

In this paper, we have analyzed the impact of firing costs on international specialization and on the pattern of innovation. The key assumption was that mature goods have a lower probability of disappearing than young goods, which is in line with empirical data on plant failure probabilities.

The results are summarized as follows. In a closed economy, firing costs bias the allocation of resources against young goods and in favor of mature goods. In an open economy, the high firing cost country will specialize in mature goods, and the low firing cost one in young goods, thus generating an international product cycle. If research can be devoted to either imitation or invention, firing costs increase the share of research allocated to imitation in a closed economy. In an open economy, the high firing cost country will imitate more than the low firing cost country, and more than if it was closed. It may even fully specialize in imitation, which cannot happen if it was closed. Invention is more sensitive to firing costs in the open than in the closed economy.

The model could be extended in various directions. While implications 
for growth are ignored in this particular setting, one could reintroduce growth by assuming externalities of the number of products on the cost of $\mathrm{R} \& \mathrm{D}$. It would be natural, following Lucas(1988) to assume that learning externalities differ across goods, in particular that they are stronger for high tech goods than for low tech goods. ${ }^{20}$ This would potentially reinforce the results. One could also examine the implications of $\mathrm{R} \& \mathrm{D}$ spillovers across countries, as empirically studied by Coe and Helpman (1995).

Other types of rigidities may also affect the pattern of specialization and innovation. The most obvious example is union-imposed work rules, which tend to bias specialization against goods with a high innovation potential, since these work rules typically block the implementation of technical progress. ${ }^{21}$ A striking episode is the docker's strike in the U.K. in 1972; the dockers opposed the use of containers. ${ }^{22}$

The model may also help to understand why European countries are more prone of industrial policy than the U.S.: because their rigid labor markets introduce a bias against high-tech goods in their specialization pattern, they are more tempted to offset this bias by subsidies and other protection measures.

\footnotetext{
${ }^{20}$ One possibility is to use Young's (1992) specification, where learning effects are bounded, so that they are endogenously lower for old goods than for young goods.

${ }^{21}$ See Krusell and Rios-Rull (1996) for a discussion from a Political Economy perspective, and Cohen and Saint-Paul (1994), for a discussion based on employment and job reallocation.

${ }^{22}$ Minimum wages may also have an effect, but not necessarily in the same direction as firing costs. According to Romer (1987), if the industrial sector is more intensive in unskilled labor than the $\mathrm{R} \& \mathrm{D}$ sector, then minimum wages may lower the return to skilled labour in the industrial sector if they reduce unskilled employment in that sector and if skilled labour and unskilled labour are complementary in the industrial sector's production function. Similarly, high-tech industries may be less vulnerable to minimum wages than low-tech industries.
} 


\section{Appendix: Complete solution of the model}

As shown in the text, the world economy can be in one of three regimes: Regime 1 where it is located on $H_{1}$, regime 2 where it is located on $H_{2}$, and regime 3 where it is located on $\mathrm{RR}$.

Let us start with regime 3 .

The equilibrium values of $\rho$ and $\nu$ are determined by the hazard frontier and the equation for RR.

$$
\begin{gathered}
\left(\frac{\rho}{m}\right)^{1 / \alpha}=\left(\frac{\nu}{m}\right)^{1 /(\alpha-1)} \\
\rho=\frac{\nu \gamma}{h+\nu} \frac{z_{1}}{z_{2}}
\end{gathered}
$$

Given $\rho$ and $\nu$, we can get the number of high-tech and low-tech goods produced in equilibrium. Using (13) we get:

$$
n_{H}=n_{H 1}=\frac{\gamma z_{1}}{h+\nu}
$$

Furthermore, in steady state the inflow of low-tech goods must be equal to the outflow. The outflow is $h . n_{L}$, while the inflow is $\rho z_{L}$. Thus, we always have $n_{L}=\rho z_{L} / h$, implying in this regime:

$$
n_{L}=n_{L 2}=\rho z_{2} / h
$$

Two relationships between the wages of production workers and the wages of researchers in each country can be obtained from the zero profit conditions in $\mathrm{R} \& \mathrm{D}$. For country 1 we must have $\Pi_{H 1}=C_{H 1}$, implying:

$$
\frac{(\mu-1) X w_{1}^{1-\sigma} \mu^{-\sigma}}{r+\nu+h}=\phi_{1} / \gamma
$$

For country 2 we have $\Pi_{L 2}=C_{L 2}$, or equivalently:

$$
\frac{(\mu-1)\left(\lambda w_{2}(1+h F)\right)^{1-\sigma} X \mu^{-\sigma}}{r+h}=\frac{\phi_{2}\left(1+h_{R} F\right)}{\gamma}
$$

Finally, all high tech goods are produced in country 1, implying that they have the same price and are produced in the same quantity. Resource equilibrium in country 1 implies that the total demand for high-tech goods 
must be equal to its supply, which is simply $1-z_{1}$. The price of a high tech good is $\mu w_{1}$ and its demand is $X w_{1}^{-\sigma}$. Therefore one must have:

$$
1-z_{1}=n_{H} X w_{1}^{-\sigma} \mu^{-\sigma}
$$

Similarly country 2 produces only low-tech goods, and the total supply is $\left(1-z_{2}\right) / \lambda$. Since the price of a low tech good is $\mu \lambda w_{2}(1+h F)$ equilibrium for country 2 's production sector is given by:

$$
1-z_{2}=n_{L} X \mu^{-\sigma} \lambda^{1-\sigma}\left(w_{2}(1+h F)\right)^{-\sigma}
$$

Finally the world price level is normalized to 1, which yields:

$$
1=n_{H} w_{1}^{1-\sigma} \mu^{1-\sigma}+n_{L} \lambda^{1-\sigma} \mu^{1-\sigma}\left(w_{2}(1+h F)\right)^{1-\sigma}
$$

The solution is fully characterized by (15)-(23). (15)-(16) allow to compute $\rho$ and $\nu$, which give the equilibrium number of goods using (17)-(18). Next, (21)-(22) allow to compute $w_{1}, w_{2}$, and $X$. Finally, the wages of researchers $\phi_{1}$ and $\phi_{2}$ can be recovered from (19)-(20).

One can check that trade is balanced from these equations. Aggregate income in country 1 is equal to $X_{1}=\left(1-z_{1}\right) \mu w_{1}$, the total value of goods sold. Similarly, aggregate income in country 2 is $X_{2}=\left(1-z_{2}\right) \mu w_{2}(1+$ $h F)$. Note, incidentally, that using (21) and (22) we can rewrite this as $X_{1}=n_{H} X w_{1}^{1-\sigma} \mu^{1-\sigma}$ and $X_{2}=n_{L} X \lambda^{1-\sigma} \mu^{1-\sigma}\left(w_{2}(1+h F)\right)^{1-\sigma}$, so that $(23)$ is equivalent to $X=X_{1}+X_{2}$. Now, the volume of low-tech goods imported by country 1 from country 2 is

$$
M_{1}=n_{L} X_{1}\left(\lambda \mu w_{2}(1+h F)\right)^{-\sigma},
$$

and its value is

$$
p_{2 L} M_{1}=n_{L} X_{1}\left(\mu \lambda w_{2}(1+h F)\right)^{1-\sigma}
$$

For country 2 we have:

$$
M_{2}=n_{H} X_{2}\left(\mu w_{1}\right)^{-\sigma},
$$

and

$$
p_{1 H} M_{2}=n_{H} X_{2}\left(\mu w_{1}\right)^{1-\sigma}
$$


Using (21)-(22), we can check that

$$
\begin{aligned}
\frac{p_{2 L} M_{1}}{p_{1 H} M_{2}} & =\frac{n_{L}\left(1-z_{1}\right) \mu w_{1}\left(\mu \lambda w_{2}(1+h F)\right)^{1-\sigma}}{n_{H}\left(1-z_{2}\right) \mu w_{2}(1+h F)\left(\mu w_{1}\right)^{1-\sigma}} \\
& =\frac{n_{L}\left(1-z_{1}\right)\left(\mu w_{2}(1+h F)\right)^{-\sigma} \lambda^{1-\sigma}}{n_{H}\left(1-z_{2}\right)\left(\mu w_{1}\right)^{-\sigma}}=1 .
\end{aligned}
$$

Let us now turn to regime 2, where the hazard frontier crosses $\mathrm{ABCD}$ on $\mathrm{H}_{2}$. While (15) is still valid, (16) must be replaced by the requirement that $R_{2}=1$, or equivalently:

$$
1=\frac{\lambda^{\sigma-1}(r+h) \gamma}{\rho(r+\nu+h)}\left(\frac{1+(h+\nu) F}{1+h F}\right)^{1-\sigma}
$$

The world allocation of research across innovation and imitation is now determined by (14) and by the requirement that $z_{H}+z_{L}=z_{1}+z_{2}$. We thus get that:

$$
\begin{gathered}
z_{H}=\frac{\rho(h+\nu)\left(z_{1}+z_{2}\right)}{\rho(h+\nu)+\nu \gamma} \\
z_{L}=\frac{\nu \gamma\left(z_{1}+z_{2}\right)}{\rho(h+\nu)+\nu \gamma}
\end{gathered}
$$

All imitation takes place in country $2: z_{L 2}=z_{L}$. The amount of innovation in country 2 is given by:

$$
z_{H 2}=z_{H}-z_{1}=\frac{\rho(h+\nu) z_{2}-\nu \gamma z_{1}}{\rho(h+\nu)+\nu \gamma}
$$

If country 2 were a closed economy, one would have $z_{H 2}=\rho(h+\nu) z_{2} /(\rho(h+$ $\nu)+\nu \gamma)$, with the same values of $\rho$ and $\nu$. Thus openness reduced innovation in country 2, more so, the larger the pool of researchers in country 1. Furthermore, while an increase in $F$ reduces $\rho$ and increases $\nu$ by the same amounts in the world economy or in country 2 if it were closed, the induced drop in the share of researchers engaged in innovation in country 2 is larger in the open economy case. To see this, just note that the total effect of $F$ on $z_{H 2} / z_{2}$ is given by

$$
\frac{\partial}{\partial F}\left(\frac{z_{H 2}}{z_{2}}\right)=\left[\frac{\partial \rho}{\partial F} \frac{\nu \gamma(h+\nu)}{[\rho(h+\nu)+\nu \gamma]^{2}}-\frac{\partial \nu}{\partial F} \frac{\rho h \gamma}{[\rho(h+\nu)+\nu \gamma]^{2}}\right]\left(1+z_{1} / z_{2}\right)
$$


The term in brackets is negative and does not depend on $z_{1}$. Thus, the effect is stronger, the stronger the size of the research pool in country 1 relative to country 2 . Since the closed economy case is equivalent to $z_{1}=0$, this also implies that the effect is stronger in an open economy than in a closed economy.

As for the allocation of production across countries, it can be readily derived from the same type of flow equilibrium. We get:

$$
\begin{gathered}
n_{H 1}=\frac{\gamma z_{1}}{h+\nu} \\
n_{H 2}=\frac{\gamma z_{H 2}}{h+\nu} \\
n_{L}=n_{L 2}=\frac{\rho z_{L 2}}{h}
\end{gathered}
$$

Equations (19)-(20) are unchanged, since it is always true that country 1 does some innovation and country 2 some imitation. So is (21), while (22) must be replaced by:

$$
1-z_{2}=n_{H 2} X \mu^{-\sigma}\left(w_{2}(1+(h+\nu) F)\right)^{-\sigma}+n_{L 2} X \mu^{-\sigma}\left(w_{2}(1+h F)\right)^{-\sigma} \lambda^{1-\sigma}
$$

Last, the price normalization equation is changed and now given by:

$1=n_{H 1} w_{1}^{1-\sigma} \mu^{1-\sigma}+n_{L 2} \lambda^{1-\sigma} \mu^{1-\sigma}\left(w_{2}(1+h F)\right)^{1-\sigma}+n_{H 2} \mu^{1-\sigma}\left(w_{2}(1+(h+\nu) F)\right)^{1-\sigma}$

This completes the characterization of equilibrium in regime 2.

As for regime 1 , it is very similar, and we briefly report the equations that are changed with respect to regime 2 .

Instead of (24):

$$
1=\frac{\lambda^{\sigma-1}(r+h) \gamma}{\rho(r+\nu+h)}
$$

Instead of (27):

$$
z_{L 1}=z_{L}-z_{2}=\frac{-\rho(h+\nu) z_{2}+\nu \gamma z_{1}}{\rho(h+\nu)+\nu \gamma}
$$

(28)-(30) are simply replaced by:

$$
n_{H 1}=n_{H}=\frac{\gamma z_{H 1}}{h+\nu}, n_{L 2}=\frac{\rho z_{L 2}}{h}, n_{L 1}=\frac{\rho z_{L 1}}{h}
$$


(22) is now unchanged, while (21) is replaced by:

$$
1-z_{1}=n_{H 1} X \mu^{-\sigma} w_{1}^{-\sigma}+n_{L 1} X \mu^{-\sigma} w_{1}^{-\sigma} \lambda^{1-\sigma}
$$

Finally the price normalization equation is:

$$
1=n_{H 1} w_{1}^{1-\sigma} \mu^{1-\sigma}+n_{L 2} \lambda^{1-\sigma} \mu^{1-\sigma}\left(w_{2}(1+h F)\right)^{1-\sigma}+n_{L 1} \lambda^{1-\sigma} \mu^{1-\sigma} w_{1}^{1-\sigma}
$$




\section{References}

Abowd, J. and F. Kramarz, "The cost of hirings and separations", mimeo, INSEE, 1994

Aghion, P. and P. Howitt, "A model of growth through creative destruction", Econometrica, 1992

and —_ _ " Research and development in the growth pro-

cess", mimeo, 1994

Alogoskoufis, George, Bean, Charles, Bertola, Giuseppe, Cohen, Daniel, Dolado, Juan and Gilles Saint-Paul, Unemployment: choices for Europe, CEPR, 1995

Butler, Alison, "Is the United States Losing its Dominance in HighTechnology Industries ?", Federal Reserve Bank of Saint-Louis Review, 1992, 74, 6, November/December, 19-34

Coe, David and Elhanan Helpman, "International R \& D spillovers", European Economic Review, 1995

Cohen, Daniel and Gilles Saint-Paul, "Uneven technical progress and job destructions", CEPR working paper, 1994

Davis, S. and J. Haltiwanger, "Gross Job Creation, Gross job destruction, and employment reallocation", Quarterly Journal of Economics, 107, 3, 819864, 1992

De Woot, Philippe, Les entreprises de haute technologie et l'Europe. Paris: Economica, 1988

Dixit, A. and Stiglitz, J.E. "Monopolistic competition and optimum product diversity", American Economic Review, 1977

Dornbusch, R., S. Fischer and P. Samuelson, "Comparative advantage, trade, and payments in a Ricardian model with a continuum of goods", American Economic Review, 1977

Dunne, Timothy J., Mark Roberts and Larry Samuelson, "The growth and failure of U.S. manufacturing plants", Quarterly Journal of Economics, 104, 671-98, 1989

Grossman, Gene, and Elhanan Helpman, Innovation and Growth in the Global Economy, MIT Press, 1991

Hopenhayn, Hugo, and Richard Rogerson, "Job turnover and policy evaluation: a general equilibrium analysis", Journal of Political Economy,1993 
Kravis, Irving E. and Robert E. Lipsey, "Technological characteristics of industries and the competitiveness of the U.S. and its multinational firms", NBER working paper, 1989

Krusell, Per and J-V. Rios-Rull, "Vested interests in a positive theory of stagnation and growth", Review of Economic Studies, 1996

Layard, Richard, Nickell, Stephen, and Richard Jackman, Unemployment, Oxford U. press, 1991

Lucas, R. "On the Mechanics of Economic Development", Journal of Monetary Economics

OECD, Main Science and Technology Indicators, 1993

OECD, Jobs Study, 1994

OECD, Main Science and Technology Indicators, 1995, 1, Paris: OECD

Pissarides, C., Equilibrium Unemployment Theory, Basil Blackwell, London, 1990

Romer, Paul "Crazy explanations for the productivity slowdown", NBER Macroeconomics Annual, 1987

"Endogenous technical change", Journal of Political Economy, 1990

Scherer, F.M., International high technology competition. Harvard U. Press, 1991

Young, Alwyn, "Learning by doing and the dynamic effects of international trade", Quarterly Journal of Economics, 1992 